\title{
Increase of energy efficiency of mine fans work on a mine vent network
}

\author{
Tetiana Bunko, ${ }^{1, *}$, Maksym Shyshov ${ }^{2}$, Oleksandr Bokii ${ }^{3}$, Anatolii Belikov ${ }^{4}$, Oleksandr \\ Zhalilov $^{5}$, and Ivan Kokoulin ${ }^{1}$ \\ ${ }^{1}$ Institute of Geotechnical Mechanics named by N. Poljakov of National Academy of Sciences of \\ Ukraine, 49005, Dnipro, Simferopolska Str., 2a, Ukraine \\ ${ }^{2}$ DTEK, 01032, Kyiv, Lva Tolstoho Str., 57, Ukraine \\ ${ }^{3}$ GE Renewable Energy, GE Ukraine, 01004, Kyiv, Shelcovichnaya Str., 42/44, Ukraine \\ ${ }^{4}$ Pridneprovsk State Academy of Civil Engineering and Architecture, 49600, Dnipro, \\ Chernyshevskogo Str., 24a, Ukraine \\ ${ }^{5}$ State Enterprise «Selydivvugillya», 85400, Selidove, K. Marksa Str., 41, Ukraine
}

\begin{abstract}
The increase of energy efficiency of main fans (MF) work is the basic condition of perfecting the mine ventilation system. During realization of multi-fan ventilation there is the non-productive «overbalancing» of vent flow from a weaker towards more powerful ventilator which causes decline of work efficiency of both. The questions of reducing the MF mutual influence on the outgoing air flow and increasing the aerodynamic quality of vent network have been studied and considered insufficiently. It is proposed to use the method of calculating the effective MF operating conditions taking into account the mutual influence of MF and areas-users of fresh air in mine ventilation network and on the basis of criterion of estimating the MF mutual influence, which will allow to enhance the energy efficiency of mine ventilation and labour safety of subsurface miners.
\end{abstract}

\section{Introduction}

The main fans (MF) are the basic users of electric energy in a mine - they consume $25 \%$ and more of mine's general power consumption. In spite of considerable successes in creating the MF with excellent stand aerodynamic parameters, in practice the efficiency of majority of them is considerably lower than normative values. It is caused by the features of the technological loading of turbomachines, determined by aerological parameters of modern mine vent networks (MVN). Their topology and aerodynamic parameters change continuously resulting in failure of the MF to work within the operative norms. Thus the unjustified excess expenditure of electric power on ventilation reduces the safety of the MF operation.

Electric power consumed for mines ventilation depends on the amount of MFs, their working modes, their mutual influence on output airflow, quality of vent network, efficiency rate of using the supplied air and a number of other factors in a mine.

\footnotetext{
*Corresponding author: bunko2017@ukr.net
} 
Electric power overuse at coal mines is caused by [1]:

a) excessive air loss. In the over-mine buildings and in the ventilating set there are always infiltrations and losses which are difficult to calculate, and impossible to fully remove;

b) feed of the excessive amount of air to the independently ventilated objects. Organizing the fully independent air feed to the object is impossible, and one ventilation direction also ventilates a number of basic and additional users. Optimization of forced air redistribution between them causes the lack of air in some of them; and the only way to vent it is to supply the excessive air into another;

c) mismatch between actual and predicted gas-emission, based on which the required amount of air for ventilation is determined. Usually actual gas-emission exceeds the prognosis, that requires excessive air supply;

d) unsatisfactory condition of the mine workings, their blocking;

e) small load on the stope;

g) irrationality of mine ventilating scheme (extent of mine works, one-wing development of the mine field and others);

h) maintained but actually not used air entries which all are the additional users of air;

i) small work-load of MF and their low efficiency;

j) negative mutual influence of MFs in case their operating mode was chosen incorrectly;

k) MF mutual influence on the outgoing air flow.

Apparently, these factors are very multidimensional, and for their removal different methods and facilities are needed: technical, organizational, multifactor modelling and others.

Certainly, a dominant role is given to correct designing of the vent system. However, even if the designer knows and takes into account all mining-and-geological and assumed mining conditions of developing the deposit, guaranteeing of complete accordance of project to the real conditions is impossible. It is impossible to take into account all the values affecting the efficiency; many of them are simply unknown to the designer.

Basic condition of increasing the ventilating energy efficiency is to reduce the negative influencing of factor a).

It is possible to control the factor b) by using local adjusting air facilities, if they are available on a mine. However researches show that such adjusting influences the MF parameters, and it is unclear which is more preferable: to redistribute air more effectively between users by means of local adjusting or accept the possible decline of MF energy efficiency due to the change (increase) of their resistance. Factor c) is clear: the more methane - the more air is needed, and the safety requirements prevail over power energy effectiveness.

Factor d) - it is possible to overcome it, but this factor is not a determining one.

Factor e) is possible to be used only to a certain degree, when a gas factor will exceed the energy efficiency of ventilation.

Factor f) depends on a designer; it's hardly possible that he assumes the miscalculations without a strong reason.

Factor g) generally must not take place, and if it can be reasonably and effectively removed it will undoubtedly increase the energy efficiency of ventilation.

Factor h), if it occurs, is either a miscalculation of mine management, or requires conducting of additional researches in order to find out why such situation occurred and how to remove it.

Factors i) and j) are mutually related, but if influence of factor i) can be reduced by the changing the MF working mode without affecting the energy efficiency of other factors, then factor $\mathrm{j}$ ) is difficult to predict. 
The effect of mutual influence of MFs on the outgoing air flow has been known for long time, however until recent time it was not possible to estimate the degree of such mutual influence and to control it.

As a result of comprehensive study of energy saving in the mine vent system, a normative document [2] «Energy saving. Means of reducing the energy consumption in coal mines' systems» (in the SOU grade) was developed and introduced into the system of Ministry of Coal Industry of Ukraine and used by the enterprises of Ministry of Power Engineering and Coal Industry of Ukraine.

It covers practically all questions of energy saving; however it does not sufficiently calculated the new approaches based on imitation modelling, when it is necessary to provide quantitative estimation of mutual influence between the elements of the single vent system - MF and MVN. The former need to be regarded as the energy consumers, and the latter - as the energy dischargers (possibly, ineffective). It is required to solve two tasks: upgrading of vent network (factor d)) and reducing the mutual influence of MF (factor j)).

Reducing influence of factor d) will reduce the resistance $R(i, j), \mathrm{Pa} \cdot \mathrm{s}^{2} / \mathrm{m}^{8}$ of the working $(i, j)$ and increase its air throughput capacity $Q(i, j), \mathrm{m}^{3} / \mathrm{s}$. Reducing influence of factor $\mathrm{j}$ ) will help decrease the air «overbalancing» between the weaker and more powerful MF, decreasing by this energy efficiency of the more powerful fan. In complex, the solution of these tasks will allow to solve the air-distribution problem in MVN without violating the requirements of Safety Rules in Coal Mines, and at the same time to keep the energy saving factor as close to optimal value as possible.

\section{Results and discussions}

The energy saving analysis of the MF work conducted in accordance with [1], shows that the range of the possible MF air gate modes can be divided into three different areas:

a) where increased energy consumption is accompanied by substantial increase of the MF feed (area of the effective adjustment);

б) where this increase does not result in substantial growth of the MF feed;

B) intermediate.

Sizes and configuration of these areas are determined by the change of rotation speed of the driving wheel, angle of its blades or combination of these methods. The location of these areas also is partially determined by the change of resistance of vent network. At certain conditions the area of the ineffective work of MF can be totally absent.

In accordance with item 5.4 [1] adjusting of the MF air gate modes to increase its energy efficiency is possible only with access to surplus amount of air. But such surplus amount of air can occur not only from ineffective MF working mode, but also from the forced violation of the MF pressure for overcoming of the harmful influence of other MF.

When developing the energy saving measures it is necessary to take into account the requirements to them:

a) after their implementation a mine must be provided with the necessary amount of air;

b) expenses on realization of energy saving measures must be substantially (no less than 2-3 times) less, than cost of saved energy;

c) the conditions of people rescue in case of emergency in the mine must not get worse.

Until present time, mutual influence of more than two MF on a general network has not been studied. The first attempts to study such mutual influence are set forth in [3] on the example of one of the most difficult in aerological respect coal mines of Ukraine - mine «1/3 Novogrodivska» SE «Selidovugol».

The principle scheme of mutual influence of the MF of mine «1/3 Novogrodivska» looks as follows (Fig. 1). 


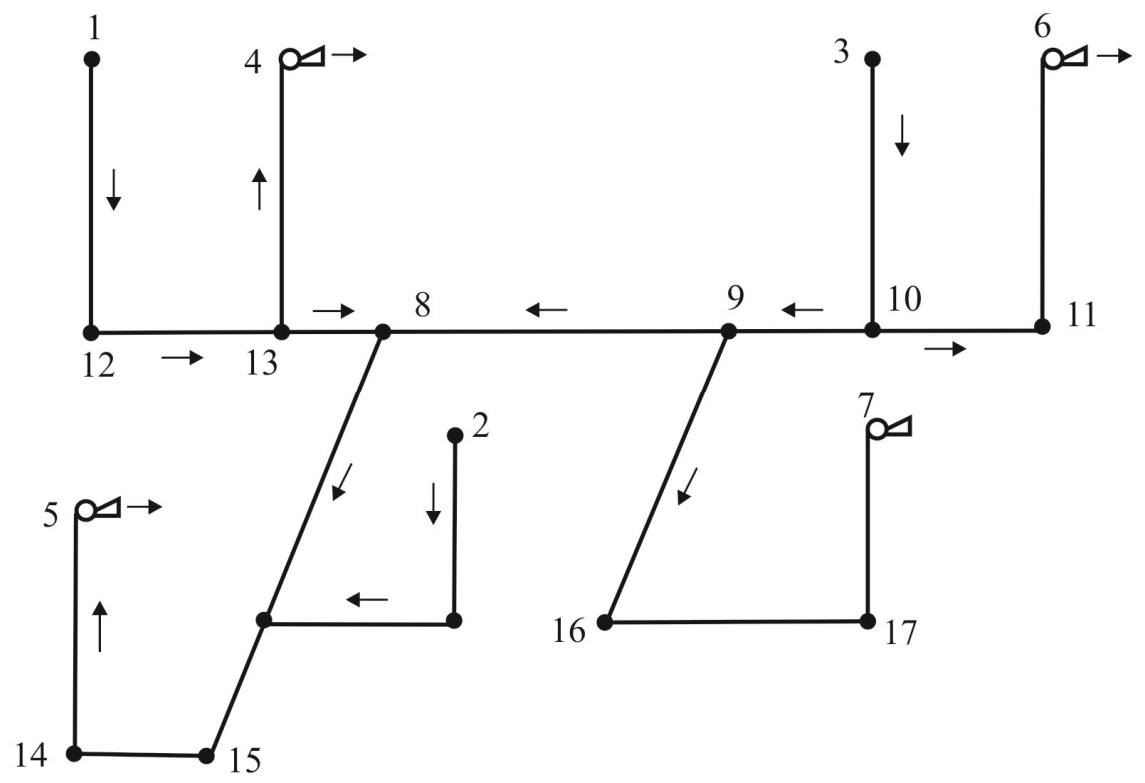

Fig. 1.Principle scheme of mutual influence of the MF of mine «1/3 Novogrodivska».

The air is fed into MVN through two air-feeding shafts (points 1 and 3) and hole (point 2), deleting of the worked air - by four MF - (points 4,5,6,7).

Thus, the system of the «MF-MVN» of mine «1/3 Novogrodivska» contains a number of ventilating subsystems, different by structure, aerodynamic parameters and degree of influence on the aerodynamic condition of the system in whole and MF mutual influence.

The air incoming through the point 1 only ventilates the area $(12,13)$. However, because of mutual influence of MF in pit \#5 (point 5) and vent shaft of mine no. 1 (point 4), part of air is redistributed to the point 8 and further to the point 5 .

Air supplied though the point 3 ventilates area $(10,11)$. However depression of MF on a pit no.4 (point 7) and MF of pit \#5 (point 5) causes redistribution of outgoing air flow from point 10 in the direction of crosscut of mines \#1 and \#3, points 9 and 7.

This forms up the areas of mutual influence of all four mine's MFs. Their boundaries are located in points 10 (for mutual MFs influence of vent shaft of mine no. 3 and of pit no. 4) and 8 (for mutual influence of all mine's MFs).

Each of these points is not actually a point of junction (division) of vent flows, but represents the aggregate of workings, the task of control of team-work of MF in which is the selecting the boundaries of the mutually affected zones of certain MFs (the MVN units in which vent flows are redistributed towards those MFs which cause larger influence on air ways).

Optimization of air-distribution in MVN taking into account the solution for above mentioned task will enhance organization of effective ventilation of mine and increase of economy of the MF use in the conditions of the reconfiguration of system in the zones (15, 14) and $(16,17)$.

Mutual influence of air flows around point 9 can be seen in more detail on a cell of the mine ventilation scheme (Fig. 2). 


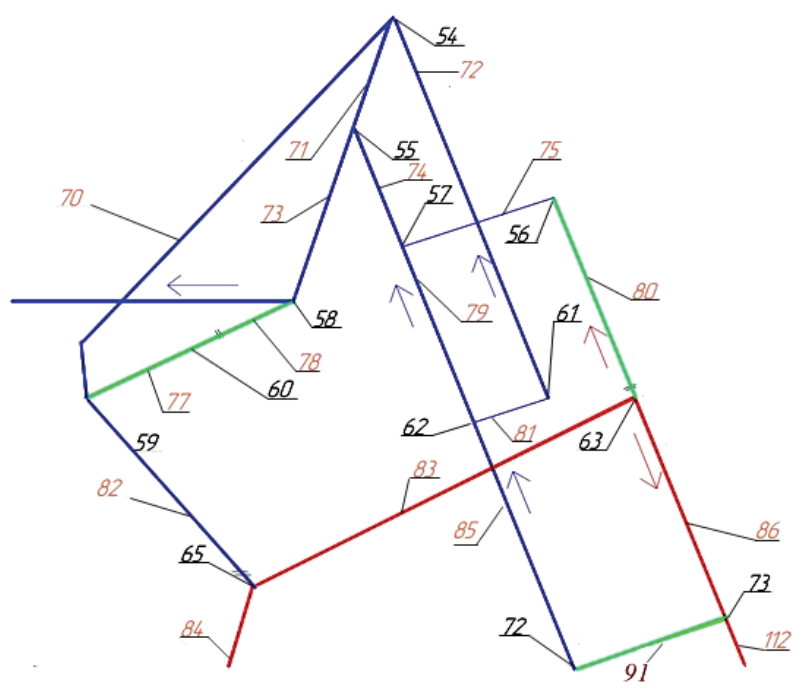

Fig. 2. To the consideration areas of MF mutual influence.

The border of the MF mutually influencing zones of the pits no. 4 and no. 5 passes in this place along the working $(65,63)$. I.e. the redistribution of airflows can performed between the workings 82 and 83 and workings 80 and 86 . In case if it would be possible to block the flows in workings 80 and 82 (vent doors on the Figure 2 can serve for this purpose) - the redistribution of fresh air could occur in the direction of pit no. 4 (working 86) improving the energy efficiency of the weaker MF. But workings 80 and 78 located consequently to air gate 82 , are the additional air users. Likewise, blocking the flow to the working 86, it would be possible to improve air-supply of these users, but this would require excluding additional air user 91 , for which 86 is the only source of fresh air. Thus, organization of sectional ventilation on the examined area is impossible, and increase of energy efficiency of one of two interacting MF can be attained only by the redistribution of flows between them by a certain criterion. This criterion was first offered in [4] in the following analytical model: total amount of air $\bar{Q}_{c o m}\left(\mathrm{~m}^{3} / \mathrm{s}\right)$ in the nodes of MF mutual influence border

$$
\bar{Q}_{\text {com }}=\sum_{\left(i, j_{k}\right) \subset U_{\text {out }}} Q\left(i, j_{k}\right) \rightarrow \sum_{\left(i, j_{k}\right) \subset U_{\text {out }}}\left\{\min \sum_{\left(i, j_{n}\right) \subset U_{l}^{b}} Q\left(i, j_{n}\right)+\max \sum_{\left(i, j_{m}\right) \subset U_{p}^{b}} Q\left(i, j_{m}\right)\right\},
$$

where $\left(i, j_{k}\right)$ is the branch of MVN, own to the mutual influence zone of MF, sense of air motion from node $i$ to node $j ; \bar{U}_{\text {out }}$ is set of MVN branches, incident with nodes of MF mutual influence border of the return-air course; $k, n, m$ are finite nodes of branches, which transport air to MF $k, n, m ; l, p$ are numbers of MF; $U_{l}^{b}, U_{p}^{b}$ are the influence zones of the MF with numbers $l$ and $p$.

If we vary productivity and the MF pressure within its production use limits, it is possible to attain optimal relation of these parameters for $\sum_{n} Q(i, j) \leq \sum_{m} Q\left(i, j_{m}\right)$ MFS without violating the requirements of Safety Rules in Coal Mines on air speed.

The results of adjusting the MF feed with the purpose to improve the ventilation energy efficiency can be received by solving the following task: 


$$
\begin{gathered}
\sum_{(i, j) \subset U_{l}} Q(i, j)=0, \quad l=1, \ldots, m_{s} \\
\sum_{(i, j) \in U_{\mu}}\left\{\operatorname{sign}[Q(i, j)] R(i, j) Q^{2}(i, j) \pm h_{b}\right\}+\sum_{(i, j) \subset\left(U_{\mu} \cap U_{b}\right)} H(i, j)=0, \quad \mu=1, \ldots, n_{s}-m_{s}+1
\end{gathered}
$$

with limitations (1) and

$$
\begin{gathered}
H(i, j)=a(i, j)-b(i, j) Q^{2}(i, j), \quad(i, j) \subset U_{b}, \\
R(i, j)=\frac{\alpha(i, j) L(i, j) P(i, j)}{[S(i, j)]^{3}}, \quad(i, j) \subset U \backslash U_{b},
\end{gathered}
$$

where $U$ is a set of the MVN branches; $U_{l}$ is the set of branches, incident to the node $l$; $U_{\mu}$ is the set of branches related to $\mu$ - independent contour; $U_{b}$ is the set of branches, represent MF; $H(i, j)$ is a depression of working or MF $(i, j), \mathrm{Pa} ; a(i, j), b(i, j)$ are the coefficients of the MF pressure characteristics, $\mathrm{Pa}$ and $\mathrm{Pa} \cdot \mathrm{s}^{2} / \mathrm{m}^{6}$ accordingly; $\alpha(i, j)$ is the coefficient of resistance, $\mathrm{Pa} \cdot \mathrm{s}^{2} / \mathrm{m}^{2} ; L(i, j)$ is the length of working, $\mathrm{m} ; S(i, j)$ is area of transversal section of working, $\mathrm{m}^{2} ; P(i, j)$ is perimeter of working, $\mathrm{m} ; n_{s}, m_{s}$ denotes

\begin{tabular}{|c|c|c|}
\hline 1 & \multicolumn{2}{|c|}{ Analysis of mutual influence of MF and air users } \\
\hline & \multicolumn{2}{|c|}{$\downarrow$} \\
\hline 2 & \multicolumn{2}{|c|}{ Forming up of mutual influence matrix of vent system elements» } \\
\hline \multicolumn{2}{|r|}{ Estimation of criteria } & Methods \\
\hline 3 & $\begin{array}{l}\text { Criterion of determination of degree of MF } \\
\text { interconnection } \Rightarrow\end{array}$ & $\begin{array}{c}\text { Control of mutually affected MF } \\
\text { zones }\end{array}$ \\
\hline 4 & Criterion of functional complexing $\Rightarrow$ & $\begin{array}{l}\text { Selection of rational functioning } \\
\text { parameters of the vent system }\end{array}$ \\
\hline \multicolumn{3}{|c|}{ \pm} \\
\hline 5 & Criterion of technical adaptiveness $\Rightarrow$ & $\begin{array}{l}\text { Conducting technical } \\
\text { modernization of MF }\end{array}$ \\
\hline & \multirow{2}{*}{\multicolumn{2}{|c|}{ Estimation of compliance with safety requirements }} \\
\hline 6 & & \\
\hline & \\
\hline 7 & $\begin{array}{r}\text { Recommendations on the increasing t } \\
\text { mutual }\end{array}$ & $\begin{array}{l}\text { ergy efficiency modesof the MF } \\
\text { tk }\end{array}$ \\
\hline
\end{tabular}
number of branches and nodes in the MVN calculation scheme accordingly; $h_{e}$ is depression of natural draft, Pa.

Figure 3 shows the structure of the solution to this task.

Fig. 3. Structure of solving the task of choosing the energy saving mode of MF work.

Scheme at Figure 3 is intentionally extended with the purpose to show the extension of the task and its place in the general problem of increasing the energy efficiency of the joint work of MF. Here we consider only the task (2)-(4) using the criterion (1) (block 1).

At the time of solving the task, the criteria of blocks 4 and 5 and the requirements of the block 6 are considered to be completed, and after we solve the task, they must be additionally analyzed. 
However on condition that at least the smooth or even gradational adjustment of MF characteristics is realizable, the solution for this task assumes conducting multiple calculations of air-flow distribution in MVN and comparison of their results. The result can be received in a simpler way by using the $K_{i}^{j}$ - coefficients of interconnection between the aerodynamic MF parameters (for better understanding: - air flow rate; $i$ is air user, $j$ is MF) and air working-user [4] (blocks 1 and 2 on the Figure 4). Such dependence, at least as applied to two MF, has almost linear character, which allows receive the result without using the optimizational calculations.

It is expedient to estimate only $K_{i}{ }^{j}$ which characterizes mutual influence of MF and the objects - users of air in MVN. For more eloquent presentation of the $K_{i}^{j}$ system, an interaction matrix is being formed $\left|K_{i}^{j}\right|=\left|\Delta Q_{i} / \Delta Q^{j_{k}}\right|$ (Fig. 4).

$$
\left(\begin{array}{cccc} 
& Q^{j_{1}} & \ldots & Q^{j_{m}} \\
Q_{i_{1}} & K_{i_{1}}^{j_{1}} & \ldots & K_{i_{1}}^{j_{m}} \\
Q_{i_{2}} & K_{i_{2}}^{j_{1}} & \ldots & K_{i_{2}}^{j_{m}} \\
\ldots & \ldots & \ldots & \ldots \\
Q_{i_{n}} & K_{i_{n}}^{j_{1}} & \ldots & K_{i_{n}}^{j_{m}}
\end{array}\right)
$$

Fig. 4. Interaction matrix «VGP - users».

If $K_{i}{ }^{j}>0$, then at increased MF rate the air in the ventilated object increases as compared to base rate, otherwise it reduces. Line 1 at Figure 5 corresponds to the first case (the user is located conditionally in parallel to the dominant MF), lines 3 and 4 correspond to the second case (conditionally consecutive connection). Line 2 corresponds to the case $K_{i}^{j}=0$.

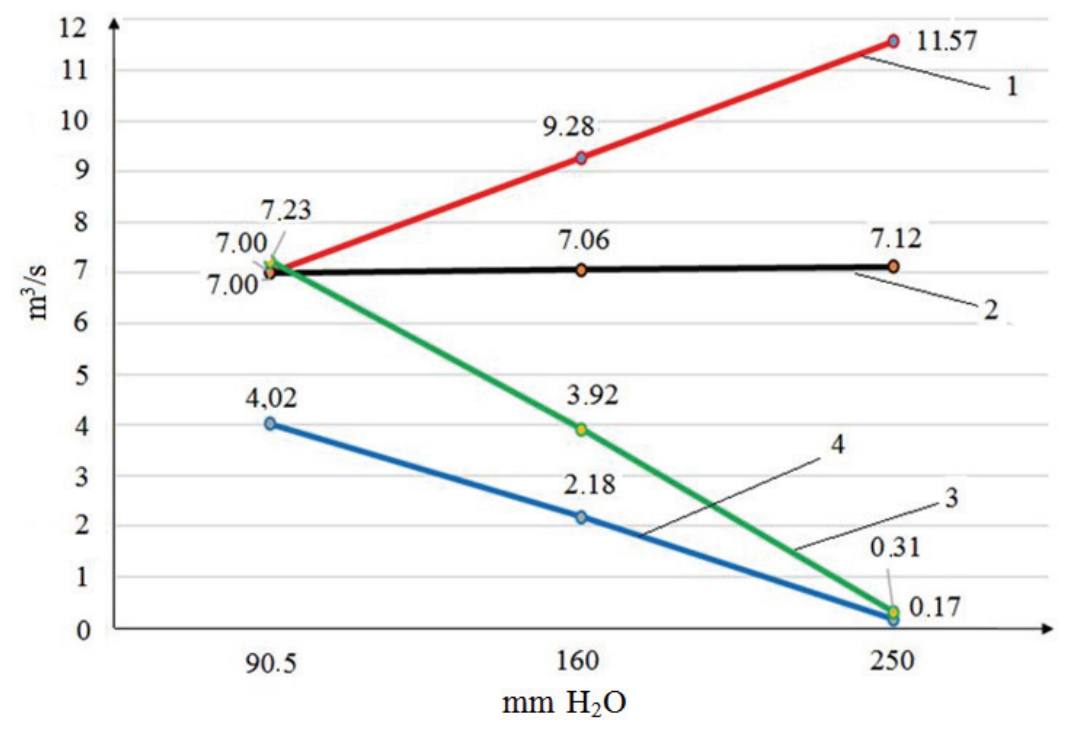

Fig. 5. Graphic illustration of Interaction «user - MF».

However, if the calculation of air-distribution is made with the real aerodynamic MF characteristics, and if compared to the results of previously made air-depression survey, one may notice certain differences. From one side, the reason for this is aging of mine 
workings, their varying blocking, and from the other side it is wear of the MF elements causing the mismatch between its real and project parameters. This factor cannot be ignored while making accurate calculations on the criterion referred to above and allowing certain error limit arising from applying the theory of aerodynamic parameters interaction. The calculation can also be made using the aerological risk matrix (interconnection of the MF and MVN risks) [5] (Table 1).

Table 1. Aerological risk matrix (interconnection of the MF and MVN risks).

\begin{tabular}{|c|c|c|c|c|c|c|c|c|c|c|c|c|c|}
\hline \multirow{3}{*}{\multicolumn{2}{|c|}{$\begin{array}{c}\text { Condition of } \\
\text { MF }\end{array}$}} & \multicolumn{12}{|c|}{ Condition of working, as a user and means of air supply } \\
\hline & & \multicolumn{4}{|c|}{ Good } & \multicolumn{4}{|c|}{ Satisfactory } & \multicolumn{4}{|c|}{ Unsatisfactory } \\
\hline & & & & & & & & & & & & & \\
\hline \multirow{3}{*}{$\begin{array}{l}\overrightarrow{8} \\
\dot{8}\end{array}$} & $Y_{1}$ & 1 & 1 & 1 & 1 & 0.75 & 0.8 & 0.75 & 0.8 & 0.8 & 0.7 & 0.8 & 0.8 \\
\hline & $Y_{2}$ & 1 & 1 & 1 & 1 & 0.8 & 0.8 & 0.75 & 0.75 & 0.65 & 0.65 & 0.65 & 0.65 \\
\hline & $Y_{3}$ & 1 & 1 & 1 & 1 & 0.75 & 0.7 & 0.75 & 0.7 & 0.65 & 0.6 & 0.65 & 0.6 \\
\hline \multirow{3}{*}{ 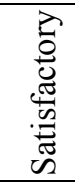 } & $Y_{4}$ & 0.9 & 0.9 & \begin{tabular}{|l}
0.9 \\
\end{tabular} & 0.9 & 0.75 & 0.7 & 0.65 & 0.7 & 0.6 & 0.6 & 0.6 & 0.6 \\
\hline & $Y_{5}$ & 0.8 & 0.8 & 0.8 & 0.8 & 0.7 & 0.65 & 0.65 & 0.6 & 0.55 & 0.55 & 0.55 & 0.5 \\
\hline & $Y_{6}$ & 0.8 & 0.8 & 0.8 & 0.7 & 0.7 & 0.65 & 0.65 & 0.65 & 0.5 & 0.55 & 0.5 & 0.5 \\
\hline \multirow{3}{*}{ 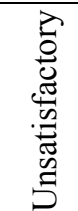 } & $Y_{7}$ & 0.6 & 0.6 & 0.6 & 0.6 & 0.5 & 0.55 & 0.55 & 0.5 & 0.45 & 0.45 & 0.4 & 0.4 \\
\hline & $Y_{8}$ & 0.5 & 0.5 & 0.5 & 0.5 & 0.4 & 0.4 & 0.35 & 0.35 & 0.3 & 0.25 & 0.25 & 0.2 \\
\hline & $Y_{9}$ & 0.3 & 0.3 & 0.3 & 0.3 & 0.25 & 0.25 & 0.25 & 0.2 & 0.15 & 0.15 & 0.1 & 0.1 \\
\hline
\end{tabular}

The following denominations are accepted in the Table: $X_{1}$ - the actual air rate, corresponds to the estimated rate; $X_{2}$ - absence of blockings; $X_{3}$ - the area cross-section of working corresponds to Safety Rules requirements to air flow speed for this type of user; $X_{4}$ - the limitations on use air flow locally regulation in area are absent; $X_{5}$ - actual rate exceeds the estimated rate (insufficient energy efficiency of ventilation); $X_{6}$ - only technological elements participating in the production process act like local resistance; $X_{7}-$ existing local resistance does not violate the Safety Rules requirements to air flow speed; $X_{8}$ - reduction of the cross-section of air entry is within the allowed limits; $X_{9}$ - the actual air rate is less then estimated rate; $X_{10}$ - the local resistance of technological character violate the Safety Rules requirements to air flow speed; $X_{11}$ - there is some dlocking in the entry requiring elimination; $X_{12}$ - ventilation conditions do not comply with operational requirements; $Y_{1}$ - the insignificant weakening of nodes fixation; $Y_{2}$ - the welded cracks within the contour; $Y_{3}$ - the even wear of equipment; $Y_{4}$ - allowable wear and deformation of nodes; $Y_{5}$-cracks within the contour; $Y_{6}$ - allowable wear of connections; $Y_{7}$ - the impermissible wear and deformation of nodes and connections. Cracks in metal constructions beyond the contour; $Y_{8}$ - unfixed elements; $Y_{9}$-any damages of wheel and guide vanes.

Multiplying the received value $Q(i, j)$ by a certain index taken from the Table 1 , it is possible to specify the $Q(i, j)$ taking into account the quality for both MVN and MF elements. The Table was made on the basis of research of the aerodynamic condition of mine «1/3 Novogrodivska», however the aerodynamic condition of other mines of the Ministry of Power Engineering and Coal Industry of Ukraine will hardly have big difference. 


\section{Conclusions}

Thus, the method of calculation and determination of the rational operating MF modes was enhanced; the approach is different because it uses the coupled nonlinear dependences between pressure and the MF feed and air rates in the separate ventilation objects and because the mutual influence estimation criterion is applied.

Of course, the above mentioned method cannot solve the task of substantial increase of ventilation energy efficiency. The problem is multydimensional and requires the complex use of technical, organizational and analytical calculation methods. However, modeling of the aerodynamic condition of the mine vent system using this method, combined with implementation of organizational and technical decisions, will allow receive positive highquality changes of ventilation, and enable to increase the energy efficiency of the MF work.

\section{References}

1. Energosberegayushchaya tekhnologiya provetrivaniya ugolnykh shakht. (1997). Donetsk: NIIGD

2. Energozberezhennya. Sposoby znyzhennya vytrat elektroenergii u systemakh ekektrospozhyvannya vugilnykh shakht. (2008). Kyiv: Ministry of Coal Industry of Ukraine

3. Bunko, T.V., Kokoulin, I.Ye., Dudnyk, M.N., Zhalilov, A.Sh. (2017). Analysis of the mutual influence of the vent system main fans in the coal mine. Znanstvena misel journal, 5, 65-71

4. Bulat, A.F., Bunko, T.V., Zhalilov, A.Sh., Yashchenko, I.A., Bokiy, A.B., Kokoulin, I.Ye. (2017). Kompleksirovaniye parametrov ventilyatorov glavnogo provetrivaniya $i$ rekonfiguriruyemoi ventilyatsionnoy seti ugolnoy shakhty. Dnipro: Zhurfond

5. Bulat, A.F., Krukovskiy, A.P., Bunko, T.V., Kokoulin, I.Ye., Yashchenko, I.A., Zhalilov, A.Sh. (2017). Mines hazard assessment using the Risk theory. Geo-Technical Mechanics, 125, 3-15 